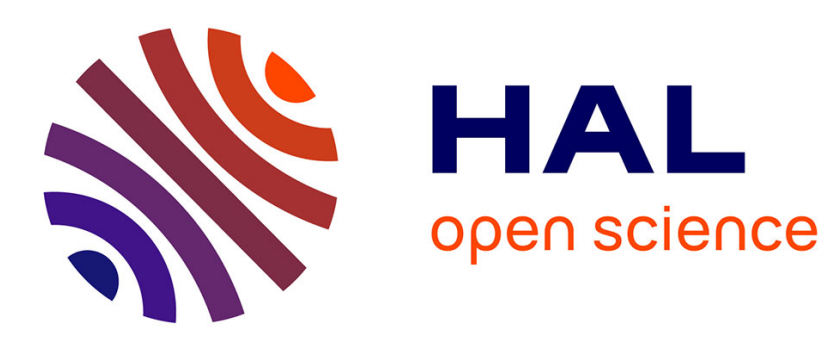

\title{
Stress Equilibrium in the Split Hopkinson Pressure Bar Test
}

\author{
X. Wu, D. Gorham
}

\section{To cite this version:}

X. Wu, D. Gorham. Stress Equilibrium in the Split Hopkinson Pressure Bar Test. Journal de Physique IV Proceedings, 1997, 07 (C3), pp.C3-91-C3-96. 10.1051/jp4:1997318 . jpa-00255475

\section{HAL Id: jpa-00255475 https://hal.science/jpa-00255475}

Submitted on 1 Jan 1997

HAL is a multi-disciplinary open access archive for the deposit and dissemination of scientific research documents, whether they are published or not. The documents may come from teaching and research institutions in France or abroad, or from public or private research centers.
L'archive ouverte pluridisciplinaire HAL, est destinée au dépôt et à la diffusion de documents scientifiques de niveau recherche, publiés ou non, émanant des établissements d'enseignement et de recherche français ou étrangers, des laboratoires publics ou privés. 


\title{
Stress Equilibrium in the Split Hopkinson Pressure Bar Test
}

\author{
X.J. Wu and D.A. Gorham \\ Faculty of Technology, The Open University, Walton Hall, Milton Keynes, MK7 6AA, U.K.
}

\begin{abstract}
The compressive split Hopkinson pressure bar (SHPB) technique allows the stresses on each end of the specimen to be measured individually. Results are presented showing a large difference between these end pressures, depending on specimen length and loading rate. The mechanisms responsible are shown to be a combination of inertial forces and non-uniform deformation due to wave propagation. Implications for the SHPB test are discussed.
\end{abstract}

Résumé. La technique de compression par barres de Hopkinson permet de mesurer individuellement les contraintes à chaque extrémité de l'éprouvette. Les résultats présentés montrent une grande différence entre ces contraintes, dépendant de la longueur de l'éprouvette et de la vitesse de chargement. Il est montré que les mécanismes responsables sont une combinaison des forces d'inertie et de la non-uniformité de la déformation due à la propagation des ondes. Les conséquences pour les essais aux barres de Hopkinson sont présentées.

\section{INTRODUCTION}

The compression split Hopkinson pressure bar (SHPB) technique is a long established method for obtaining properties of materials at high strain rates (Kolsky [1]). During the SHPB test a cylindrical specimen is compressed axially between two instrumented, coaxial bars. Strain gauges mounted on the incident and transmitter bars enable the stress waves to be measured. One dimensional studies of wave propagation shows that the following quantities can be derived from measurements of the incident loading pulse $\varepsilon_{i}$, the transmitted pulse $\varepsilon_{t}$ and the reflected pulse $\varepsilon_{r}$ (Lindholm [2]). The stress on the front (loaded) face of the specimen is

$$
\sigma_{s 1}=E \frac{A}{A_{s}}\left(\varepsilon_{i}+\varepsilon_{r}\right)
$$

where $E$ and $A$ are the Young's Modulus and area of the pressure bar, and $A_{s}$ the area of the specimen. The stress on the rear face of the specimen is given by

Hence the average stress is

$$
\sigma_{s 2}=E \frac{A}{A_{s}}\left(\varepsilon_{1}\right)
$$

$$
\sigma_{s}=\frac{E A}{2 A_{s}}\left(\varepsilon_{i}+\varepsilon_{r}+\varepsilon_{t}\right)
$$

The average strain $\varepsilon_{s}$ and strain rate $\dot{\varepsilon}_{s}$ in the specimen are

$$
\begin{aligned}
& \varepsilon_{s}=\frac{c_{0}}{l_{0}} \int_{0}^{t}\left(\varepsilon_{i}-\varepsilon_{r}-\varepsilon_{t}\right) d t \\
& \dot{\varepsilon}_{s}=\frac{c_{0}}{l_{0}}\left(\varepsilon_{i}-\varepsilon_{r}-\varepsilon_{t}\right) d t
\end{aligned}
$$

where $c_{0}$ is the phase velocity of infinitely long waves, and $l_{0}$ is the initial length of the specimen. 
In order for these average values to represent useful material properties, it is assumed that stress equilibrium exists in the specimen. In this case, the instantaneous values of the three strain-time histories must satisfy the approximation

$$
\varepsilon_{r}=\varepsilon_{t}-\varepsilon_{i}
$$

and consequently equations (3) - (5) reduce to

$$
\begin{aligned}
& \sigma_{s}=\frac{E A}{A_{s}} \varepsilon_{t} \\
& \varepsilon_{s}=-\frac{2 c_{0}}{l_{0}} \int_{0}^{t} \varepsilon_{r} d t \\
& \dot{\varepsilon}_{s}=-\frac{2 c_{0}}{l_{0}} \varepsilon_{r}
\end{aligned}
$$

Several authors, including [2], [3] and [4], have concluded that any longitudinal stress differences were within experimental accuracy and could be safely neglected. However, this conclusion was drawn from their experimental evidence obtained at comparatively low strain rates, where $\dot{\varepsilon}_{s}<1000 \mathrm{~s}^{-1}$. Nowadays the SHPB technique is used for achieving strain rates to $10^{4} \mathrm{~s}^{-1}$ or higher (e.g. Follansbee et al. [5], Couque and Walker [6]), and the conclusion of uniformity reached at lower strain rates may no longer be appropriate. Evidence for a considerable degree of non-uniformity has arisen from experimental and numerical studies of high strain rate compression tests, including Lichtenberger et al. [7] and Couque and Walker [6]. In SHPB tests at these high strain rates, some authors have used equations (3) - (5) to derive material characteristics, while others have used (7) - (9).

In this paper we have investigated stress equilibrium within the compression SHPB specimen by separately calculating the stresses at the front and rear specimen-bar interfaces, using equations (1) and (2), over a range of impact velocities and specimen lengths. There is a large difference between the two stresses for longer specimens and higher impact velocities, indicating non-uniform deformation of the specimen under these conditions. These results are discussed in the context of inertial forces and wave propagation.

\section{EXPERIMENTS}

The pressure bars used in this study are made from $6.7 \mathrm{~mm}$ diameter titanium 6Al4V alloy rod. The $70 \mathrm{~mm}$ long projectile was cut from identical material, and accelerated in a gas gun. The annealed copper specimens ( $99.9 \%$ purity) were $4.7 \mathrm{~mm}$ in diameter and between $0.75-4 \mathrm{~mm}$ in length.

The pressure bars were instrumented with miniature semiconductor strain gauges which are small enough to be bonded directly to the bar surface without machining a flat. In order to avoid adding mainsborne noise that is found on the output of conventional power supplies, the gauges were individually powered by voltage stabilised batteries. Both bars were calibrated dynamically to give an overall measurement error of better than $\pm 1 \%$.

The signals from each bar are recorded by a digital oscilloscope, and data processing and analysis have been carried out using programs developed in the MATLAB environment. These programs include procedures for gauge calibration, correction of wave dispersion and other signal processing functions, synchronisation of the three measured pulses, and generation of the output graphs.

\section{DISPERSION}

The propagation of short, longitudinal stress pulses in bars is dispersive, leading typically to an increase in risetimes and the development of the familiar Pochhammer-Chree oscillations. Since the bar signals ite normally monitored at some distance away from the specimen interfaces, dispersion can seriously affect the accuracy of the SHPB technique. In addition, if dispersion in the input bar is significant, then the specimen is subjected to an oscillatory component of the loading which can obscure the rate dependent properties that are to be measured.

These dispersive effects can be reduced by ramping the projectile loading pulse, using, for example, a buffer disc (Frantz et al. [8]), a rounded bar end, or a pre-loading bar either with (Ellwood et al. [9]), or without (Parry et al. [10]), a dummy specimen. In the present work we have increased the pulse risetime by attaching a double thickness of $80 \mathrm{~g} \mathrm{~m}^{-2}$ copy paper to the impact face of the incident bar. This simple technique produces almost oscillation-free loading pulses. 

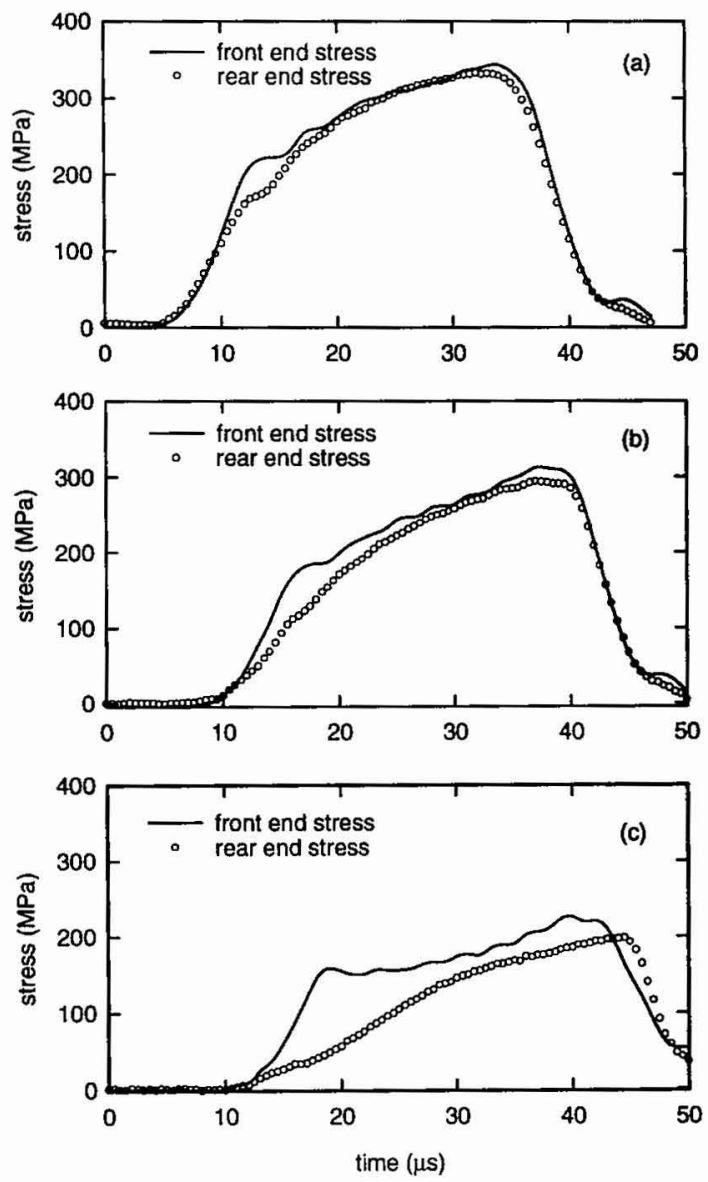

Figure 1: Comparison of stresses at front and rear ends of the specimens for different specimen lengths: (a) $\mathrm{l}_{0}=0.76 \mathrm{~mm}$; (b) $\mathrm{l}_{0}=1.5 \mathrm{~mm}$; (c) $\mathrm{l}_{0}=3.9 \mathrm{~mm}$. Impact velocity $=22.3 \mathrm{~ms}^{-1}$.

Although large scale oscillations can be removed experimentally, a certain amount of dispersion still affects the stress pulses in the pressure bars. In order to obtain precise histories of the stress conditions at the specimen interfaces a new method of empirical dispersion correction (Gorham and Wu [11], [12]) was applied to the recorded pulses. In this method, the dispersive characteristics of the bar are accurately derived from the impact of small spheres. This empirically measured phase data gives a better correction of dispersed pulses than techniques based on theoretical bar characteristics, and is very simple to apply on a routine basis.

\section{COMPARISON OF END FORCES}

Equations (1) and (2) allow the average stress on each end of the specimen to be calculated independently, and the front and rear stress histories obtained in this way for three specimens of different lengths are shown in Figure 1. In each case the specimen diameter was $4.8 \mathrm{~mm}$, and the projectile impact velocity on the end of the input bar was nominally $22.3 \mathrm{~ms}^{-1}$. The top graph, corresponding to the shortest specimen $(0.76 \mathrm{~mm}$ long), shows that the front and rear stresses are very close throughout the loading history, apart from a brief peak at the top of the initial rise. The middle graph, from a test with a $1.5 \mathrm{~mm}$ long specimen, shows a rather greater stress difference at the initial rise, with a significant gap persisting over the rest of the loading time. The longest specimen, illustrated in Figure 1(c), was $3.9 \mathrm{~mm}$ long. This follows the same pattern but shows a much larger difference over the whole loading cycle. 

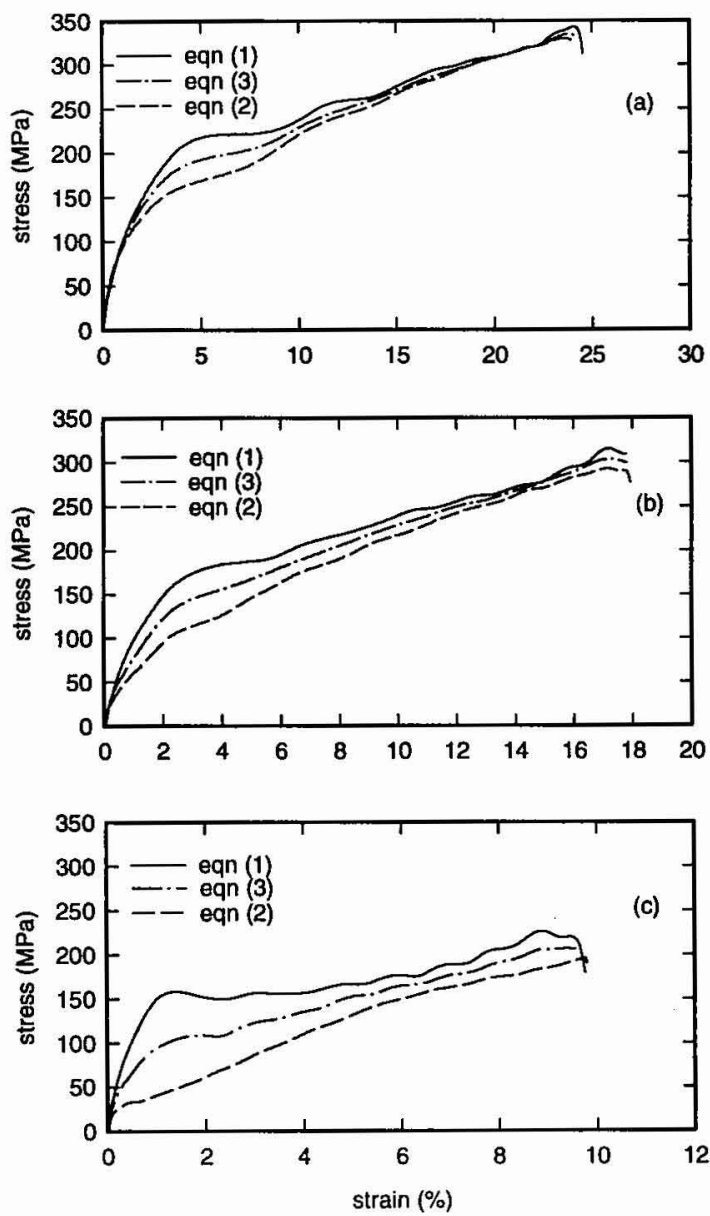

Figure 2: Stress-strain relations from the tests in Figure 1. (a) $\mathrm{l}_{0}=0.76 \mathrm{~mm}$; (b) $\mathrm{I}_{0}=1.5 \mathrm{~mm}$; (c) $\mathrm{l}_{0}=3.9 \mathrm{~mm}$. Stress calculated from equations shown. Strain calculated from equation (4).

Under the same loading conditions, the deformation of short specimens corresponds to a higher strain rate than longer ones. Hence, to provide a comparison between the same strain values, Figure 2 shows the stress results from these examples plotted against average strain. Again the discrepancy between front stress and rear stress can be clearly seen to increase with specimen length. Figure 3 shows the variation in average strain rate throughout each test. The shortest specimen corresponds to the highest strain rate, and also to the largest variation of strain rate throughout the duration of the test.

The stress histories on the front and rear faces of $2.5 \mathrm{~mm}$ long specimens obtained under two different impact velocities are compared in Figures 4(a) and (b). As in Figure 1, the higher velocity of $22.3 \mathrm{~ms}^{-1}$ in Figure 4(b). gives rise to a significant stress non-uniformity throughout the test. Although the two stresses approach each other as time increases, stress equilibrium is never achieved. At the lower impact velocity of $13.4 \mathrm{~ms}^{-1}$, however, the stress equilibrium condition is established approximately $12 \mu \mathrm{s}$ after the initial impact, corresponding to about $2 \%$ strain.

\section{DISCUSSION}

The results clearly show that there can be a difference between the end forces in a compression SHPB specimen, depending on specimen length and the rate of loading. When it occurs, the difference is largest just after the main rise of loading, and then progressively diminishes as the test progresses. An important practical consequence of such a large stress gradient is that considerable variation in stress-strain results may be found comparing equations (3) - (5) with (7) - (9) to process data from the SHPB test. A more fundamental problem with such non-uniform deformation is that any external measurements under these conditions will probably not represent valid bulk material properties. 


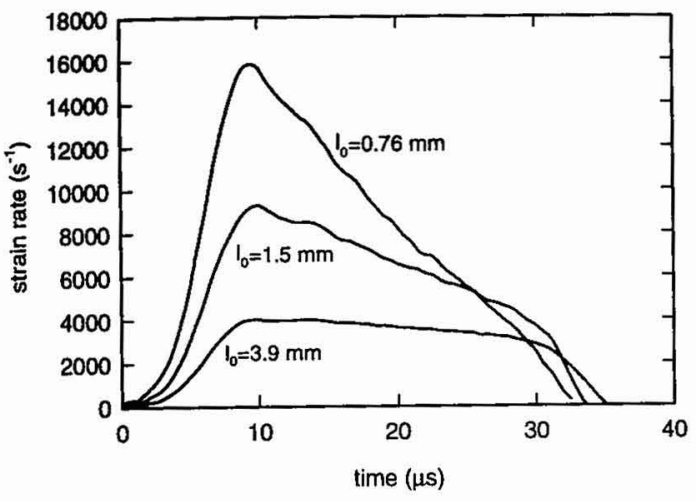

Figure 3: Average strain rate histories for the tests in Figure 1, calculated by equation (5)
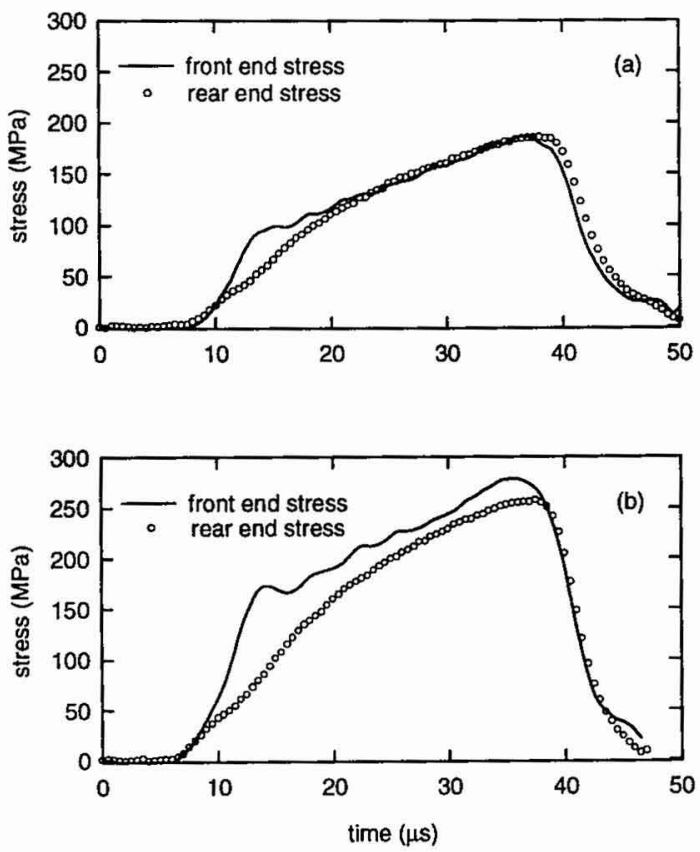

Figure 4: Comparison of stresses at front and rear ends of a $2.5 \mathrm{~mm}$ specimen at different impact velocities: (a) $13.4 \mathrm{~ms}^{-1}$; (b) $22.3 \mathrm{~ms}^{-1}$.

The first mechanism that must be considered is that of inertia. Even if the specimen is deforming uniformly, then a stress gradient is developed along its length because of inertial forces. Analyses of this effect based on considerations of energy balance have been published by several authors, and the following expressions for the pressures $\sigma_{\mathrm{s} 1}$ and $\sigma_{\mathrm{s} 2}$ at the front and rear specimen faces were derived by Gorham [13].

$$
\begin{aligned}
& \sigma_{s 1}=\sigma_{y}-\rho\left(\frac{a^{2}}{8}+\frac{h^{2}}{3}\right) \ddot{\varepsilon}+\rho\left(\frac{a^{2}}{16}-\frac{h^{2}}{3}\right) \dot{\varepsilon}^{2}+\frac{\rho h \dot{v}}{2} \\
& \sigma_{s 2}=\sigma_{y}-\rho\left(\frac{a^{2}}{8}-\frac{h^{2}}{6}\right) \ddot{\varepsilon}+\rho\left(\frac{a^{2}}{16}+\frac{h^{2}}{6}\right) \dot{\varepsilon}^{2}-\frac{\rho h \dot{v}}{2}
\end{aligned}
$$

where $\sigma_{y}$ is compressive yield stress of the specimen, $\rho$ its density, $a$ and $h$ are the specimen radius and thickness respectively, and $v$ is the velocity of its rear face. In the current tests, the term containing $\ddot{\varepsilon}$ is the largest, and the terms in $\dot{\varepsilon}^{2}$ and $\dot{v}$ can be neglected. Hence the difference between the two end pressures is given by

$$
\sigma_{s 2}-\sigma_{s 1} \approx \Delta \sigma_{i}=\rho \frac{h^{2}}{2} \ddot{\varepsilon}
$$

Table 1 presents this stress difference, $\Delta \sigma_{i}$, calculated from equation 12 , for each of the specimen lengths used in the experiments. The values of $\ddot{\varepsilon}$ are taken from the initial slopes of each of the lines in Figure 3 .

Table 1: Values of $\Delta \sigma_{i}$ calculated from equation (12)

\begin{tabular}{|c|c|c|}
\hline specimen length $/ \mathrm{mm}$ & $\ddot{\varepsilon} / \mathrm{s}^{-2}$ & $\Delta \sigma_{i} / \mathrm{MPa}$ \\
\hline 0.76 & $3 \times 10^{9}$ & 8 \\
\hline 1.5 & $1.8 \times 10^{9}$ & 18 \\
\hline 3.9 & $8 \times 10^{8}$ & 55 \\
\hline
\end{tabular}


These predicted values for $\Delta \sigma_{i}$ will apply during the rapid rise of strain rate at the beginning of the test. They are a significant fraction of the differences between the front and rear stresses seen in Figure 1, and vary with specimen length in the same manner. However, as Figure 3 indicates, the strain rate decreases over most of the deformation, and hence the later contribution from the $\ddot{\varepsilon}$ term will be a small, negative value. Although at this stage the other inertia terms may be more significant, inertia does not fully explain the continuing difference between the end pressures. In this case non-uniform deformation due to wave propagation effects is also likely to be playing a significant role.

It well known that a steady stress state in the specimen is built up by multiple reflections of elastic and plastic stress waves (for example Parry et al. [14], Dioh et al. [15]). It is clear that the higher the wave propagation speed and the shorter the specimen, the quicker is uniformity of stress and strain achieved. There is a considerable elastic impedance mismatch between the copper specimen and titanium bars, and effects similar to those in [14] and [15] are expected in the present work.

The numerical results of Lichtenberger et al. [7], [16] suggest that the end pressures should converge within about $20 \mu \mathrm{s}$ for our $3.9 \mathrm{~mm}$ long specimen. Although the signals in Figure 1(c) do approach in this time scale, they do not meet at any stage in the test. This gap is likely to be a lasting consequence of the non-uniform strain during the early stages of deformation. If the specimen becomes slightly tapered towards the rear face, then both the increased stress and strain at the front end will contribute to the total force, and hence to the apparent increase in stress. However, the amount of non-uniformity required to explain the observed effects is small, and has not been detected in recovered specimens.

\section{CONCLUSION}

The results have shown that inertia and wave propagation effects can make a substantial contribution to the observed stress differences between the ends of compression SHPB specimens. Under these conditions, using equation (7), which is equivalent to calculating the rear end stress, will produce a much lower value than the average stress calculated from equation (3). Although the average stress is the more reliable measure, a significant stress gradient should be taken as an indication that the measurements may not represent valid, uniform material characteristics. The condition of stress uniformity needs to be examined for each experimental configuration in order to check the validity of SHPB results.

Using thinner specimens will help to achieve a more uniform deformation state more quickly, but wil! increase the effects of friction (Gorham et al. [17]), and cause a wider variation of strain rate throughout the test. Increasing the rise time of the loading pulse by an appropriate experimental means will reduce the effects of dispersive distortion, and improve the uniformity of deformation.

\section{Acknowledgements}

This work was sponsored jointly by DRA and the EPSRC Materials Programme. We thank J. Butler and C. Bluck for technical support.

\section{References}

[1] Kolsky H. Proceedings of the Physical Society B 62 (1949) 676-700.

[2] Lindholm U.S. J. Mech. Phys. Solids 12 (1964) 317-335.

[3] Lindholm U.S. and Yeakley L.M. Experimental Mechanics 8 (1968) 1-9.

[4] Billington E.W. and Brissenden C. Int. J. Mech. Sci. 13 (1971) 531-545

[5] Follansbee P.S., Regazzoni G. and Kocks U.F. in Mechanical properties at high rates of strain $1984 \mathrm{ed}$ J. Harding (The Institute of Physics, Bristol, 1984) 71-80.

[6] Couque H. and Walker J.D. J de Physique IV 4 (1994) C8 23-28.

[7] Lichtenberger A., Gazeaud G. and Lach E. J. de Physique 49 (1988) C3 589-594.

[8] Frantz C.E., Follansbee, P.S. and Wright W.T. (1984) in Proc. 8th Int. Conf. on High Energy Rate Fabrication (1984).

[9] Ellwood S., Griffiths L.J. and Parry D.J. J. Phys. E: Sci. Instrum. 15 (1982) 280-282.

[10] Parry D.J., Walker A.G. and Dixon P.R. Meas. Sci. and Technol. 6 (1995) 443-446.

[11] Gorham D.A. and Wu X.J. Meas. Sci. and Technol. 7 (1996) 1227-1232.

[12] Gorham D.A. and Wu X.J. Paper elsewhere in this volume.

[13] Gorham D.A. J. Phys. D: Appl. Phys. 22 (1989) 1888-1893.

[14] Parry D.J., Dixon P.R., Hodson S. and Al-Maliky N. J. de Physique IV 4 (1994) C8 107-112.

[15] Dioh N.N., Ivankovic A., Leevers P.S. and Williams J.G. Proc. R. Soc. Lond. A 449 (1995) 187-204.

[16] Gazeaud G. Report R 128/87 (Institute Saint-Louis, 1987).

[17] Gorham D.A., Pope P.H. and Cox O. in Mechanical properties at high rates of strain 1984 ed. J. Harding (The Institute of Physics, Bristol, 1984) 151-158. 